\title{
E-Health-Gesetz
}

\section{So funktioniert Telematik nicht}

\section{Ein neues Gesetz bürdet den Ärzten neue Verwaltungsservices auf, ohne dass die Infrastruktur existiert. Das Scheitern ist programmiert.}

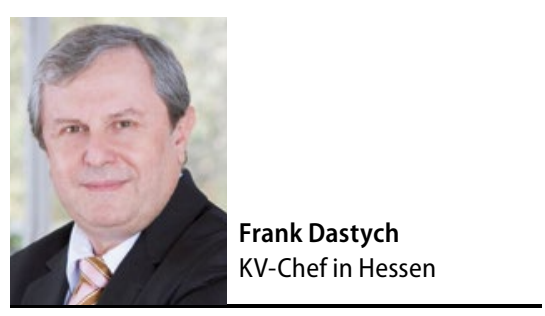

_ Stellen Sie sich vor, Sie müssen schnell mit dem Auto von Frankfurt nach Hamburg. Das Problem: Nur die Hälfte der Strecke ist Autobahn, der Rest sind Landstraßen und Feldwege mit Schlaglöchern. Genauso verhält es sich aktuell mit dem Gesetz für sichere digitale Kommunikation und Anwendungen, kurz E-Health-Gesetz, das der Bundestag nach langer Diskussion im Dezember 2015 verabschiedet hat.

Zuallererst fehlt es an einer ausreichend vorhandenen Telematik-Infrastruktur. Denn es gibt bisher keine flächendeckende Breitbandvernetzung. In Nordhessen z. B. gibt es keinen Anbieter, der fünf Praxen und eine Klinik vernetzen würde. Entsprechende Infrastrukturmaßnahmen der Politik? Fehlanzeige. Im Gesetz fehlt sogar jegliche Pflicht für die Telekommunikationsanbieter! Die Politik spricht seit Jahren vom „schnellen Internet für ganz Deutschland“, tut aber nichts. Dies schadet nicht nur im Health-Bereich, sondern der gesamten Infrastruktur in den Regionen.

\section{Patientenfreundliche Neuerungen blieben auf der Strecke}

Würde es in diesem Gesetz wirklich um E-Health gehen, hätte sich der Gesetzgeber um Neuerungen gekümmert, die tatsächlich einen Mehrwert für die $\mathrm{Pa}$ tienten hätten - z.B. den elektronischen Arztbrief oder das Übergabemanagement zwischen stationärem und ambulantem Sektor. Genau dies wäre, nebenbei bemerkt, bereits heute über das sichere Netz der KVen möglich. Doch die Politik wartet stattdessen lieber auf die Industrie. Damit wird klar, wem dieses Gesetz dient. Der E-HealthBereich wird auf diese Weise zum
Marktplatz, auf dem patientenbezogene Daten gehandelt werden.

Die unbequemen Lasten werden bei alledem mal wieder den Ärzten aufs Auge gedrückt. Beispiel Versichertenstammdatenmanagement (VSDM): Zukünftig sollen beim Einlesen der elektronischen Gesundheitskarte (eGK) in der Arztpraxis die auf der Karte gespeicherten Versichertendaten geprüft werden.

\section{Gemächlicher Datenabgleich}

Dazu läuft im Hintergrund ein Prozess $a b$, der zu zeitlichen Verzögerungen im Praxisablauf führen wird. Denn während des Einlesens wird eine Verbindung zur jeweiligen Krankenkasse aufgebaut und die auf der eGK abgespeicherten Versichertenstammdaten mit den bei der Krankenkasse hinterlegten Daten abgeglichen. Es braucht nicht viel Fantasie, um sich vorzustellen, dass es hier am Quartalsanfang zu einer Überlastung der Leitungen kommt, da zeitgleich eine große Zahl von Karten eingelesen und damit ein erheblicher Datenfluss ausgelöst wird. Kommt es zu einer Überlastung, sinkt die Übertragungsgeschwindigkeit, die eGK verbleibt länger als geplant im Lesegerät, die Aufnahme des Patienten dauert länger - und der gesamte Praxisablauf verzögert sich.

Die Vertreterversammlung der KV Hessen hat hauptsächlich aus diesem Grunde unsere Mitglieder im Herbst aufgefordert, sich nicht am VSDM zu beteiligen. Die Aktualisierung der Patientendaten ist originäre Aufgabe der Krankenkassen - für diese bürokratischen Aufgaben haben die Praxen angesichts von Ärztemangel und zunehmender Morbidität keine Zeit. Wenn dieser Service trotz- dem gewünscht ist, muss uns die Politik sagen, auf welche anderen Aufgaben wir verzichten sollen. Vielleicht auf die Versorgung akut Kranker? Oder chronisch Kranker? Oder auf Prävention?

Letztendlich ist dies ein weiteres Gesetz gegen die Ärzteschaft. Ein Gesetz, bei dem sich die Politik an die Seite der Industrie stellt. Ein Gesetz, das so zum Scheitern verurteilt ist. Es wird Milliarden verschlingen, ohne dass es am Ende irgendeinen Vorteil für die Patienten bringt. Die einzigen vernünftigen und jetzt schon nutzbaren Anwendungen werden sogar noch kaputt gemacht. Die E-Health-Industrie dankt.

- Der Autor ist Vorstandsvorsitzender der KV Hessen

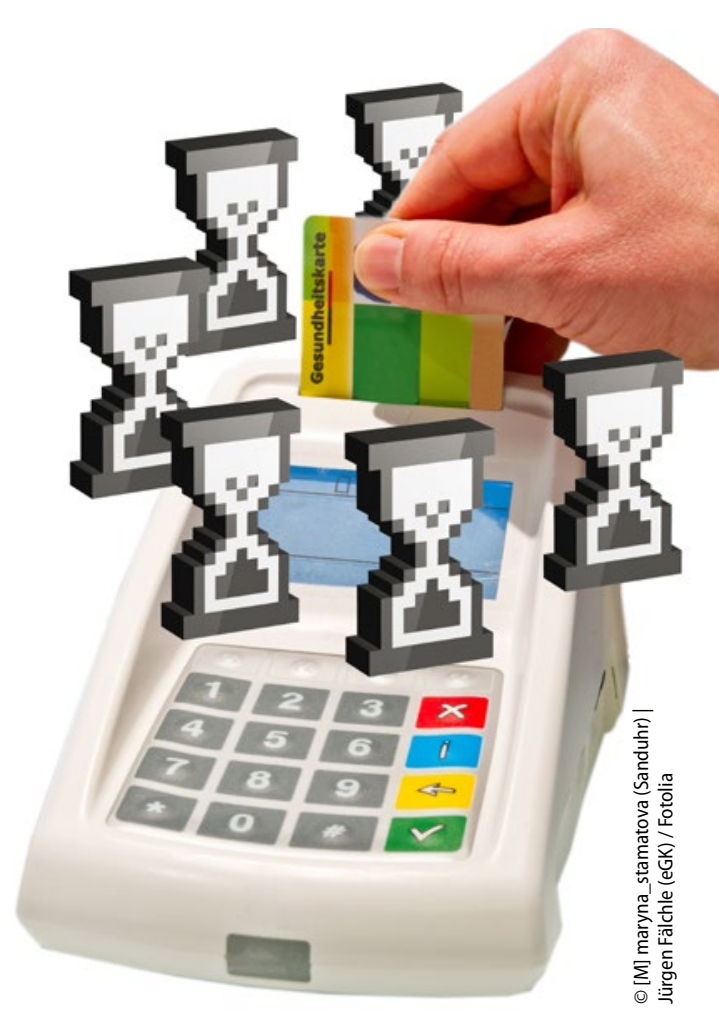

E-Card im Alltag:

Und das Praxisteam wartet ... 